\title{
Does access to health insurance reduce the risk of miscarriages? Evidence from Mexico's Seguro popular
}

\author{
Tobias Pfutze ${ }^{1}$
}

Received: 7 October 2014/Revised: 6 July 2015/Accepted: 19 September 2015/

Published online: 7 October 2015

(C) The Author(s) 2015. This article is published with open access at Springerlink.com

\begin{abstract}
This paper analyzes whether Mexico's de-facto non-contributory health insurance program Seguro Popular had an effect on the risk of miscarriage during pregnancy. Using data on pregnancies over the 2004-08 period from the 2009 round of the National Survey on Demographic Dynamics (ENADID), and employing the staggered roll-out of the program as an identification strategy, it is found that it resulted in a significant reduction in the risk of a miscarriage. For the target population, a one percentage point increase in eligibility is found to decrease miscarriages by .04 percentage point at the average.
\end{abstract}

Keywords Miscarriages $\cdot$ Health insurance $\cdot$ Mexico

JEL Classification $\mathrm{I} 13 \cdot \mathrm{I} 15 \cdot \mathrm{I} 18 \cdot \mathrm{O} 12$

\section{Introduction and background}

Since the start of its roll-out in 2004, Mexico's health insurance system Seguro Popular has received considerable attention in the academic, as well as, policy literatures. These can be subdivided into three broad topics: (i) the incidence of a non-contributory health insurance on labor market decision, in particular informality; (ii) whether or not the program was successful in its stated aim of increasing access to quality health services and reducing out of pocket expenses on health care, and, lastly; (iii) the effect of the insurance on health outcomes. Regarding this last

Tobias Pfutze

tpfutze@fiu.edu

1 Department of Economics, Florida International University, 11200 SW 8th Street, Miami, FL 33199, USA 
point, thus far, most of the studies have failed to find any significant effect (Barros 2008; Martínez and Aguilera 2010; King et al. 2009; Knox 2008). However, as most health outcomes, especially in adults, are slowly moving targets, it is doubtful whether one would expect to find any significant effect of a recently established program (Scott and Aguilera 2010). Focusing on shorter-term health outcomes, some authors have recently found evidence that program affiliation results in lower levels of cholesterol (Ruvalcaba and Parker 2010), lower blood pressure (Ruvalcaba and Parker 2010; Bleich et al. 2007), and lower infant mortality (Pfutze 2014).

The present paper contributes to this last line of research. Similar to infant mortality, any effect of improved health care access on the likelihood of a miscarriage can be expected to manifest itself in the short-run. While there are some data-related problems (a relatively rare outcome, combined with a noisy measurement of program exposure) that affect statistical power, it is found that the program significantly reduced the risk of a miscarriage by around $0.04 \%$ points for each percentage point increase in coverage of the target population. It is also shown that this effect is not changed much by potential selection on the outcome variable. The upshot is that during the first four and a half years of roll-out alone, Seguro Popular has prevented an estimated 47,986 miscarriages. These are economically important positive welfare effects that need to be included into every coherent assessment of the policy.

Regarding the literature in the other lines of research, following Santiago Levy's early critique that the program will undermine efforts to bring Mexico's labor force into the formal sector (Levy 2008), several studies have set out to determine whether or not it changed the incentives to pursue formal vs. informal sector employment (Aterido et al. 2011; Azuara and Marinescu 2013; Barros 2008; Bosch and Campos-Vázquez 2014; Camacho et al. 2014; Campos-Vázquez and Knox 2013; Duval-Hernández and Smith-Ramírez 2011). In most cases, they either find no effect or a statistically significant, but fairly small shift toward informality. Other studies focus on changes in the access and use of health services in response to the program (Knox 2008; Sosa-Rubi et al. 2009), or the avoidance of catastrophic health expenditures (Grogger et al. 2010; Gakidou et al. 2006; Knaul et al. 2006; King et al. 2009). The principal findings are that the program has largely succeeded on both counts.

The Seguro Popular health insurance program started its roll-out in January 2004, after a pilot program in 2002/03. The roll-out occurred at the level of locality, with localities that had a large proportion of its population uncovered being enrolled first. The insurance is de-facto non-contributory for all beneficiaries as it is free of charge for households in the bottom two wealth quintiles as determined by a uniform questionnaire, and for the immediate family of every child born after December 1 , 2006. According to the Mexican health ministry, less than $1 \%$ of the affiliated households pay for coverage. Its declared aim is to provide health insurance to the more than $50 \%$ of Mexico's population, mostly self-employed and/or in the informal sector of the economy, that did not get coverage through any of the employment linked programs or through the private market. ${ }^{1}$ It does not replace any of the existing public health services, but adds a lowest tier of coverage to the

\footnotetext{
1 See Frenk et al. (2006) for a detailed discussion on the motivation for and description of the program.
} 
existing system. Its distinguishing feature is that it is run as an insurance, not a direct provider of health services. It certifies health care providers and buys services from a list of close to 300 covered interventions (plus a separate list of interventions that would result in catastrophic health expenditures) at fixed prices. A large number of these interventions are related to pre-natal care. ${ }^{2}$ While in theory any provider can be certified, the lion's share is made up of clinics and hospitals run by the federal and state level ministries of health (Lakin 2010).

\section{Data and empirical strategy}

Two different data sources are used. For one, the data on the Seguro Popular roll-out have been provided directly by the Mexican Health Ministry. Starting in January 2004 , it shows the number of affiliated individuals in each municipality on a monthly basis. These monthly observations are available until late 2011, at which point roll-out was considered complete (meaning that every person in the country had the right to enroll). All other data come from the 2009 round of Mexico's National Survey on Demographic Dynamics (ENADID, by its Spanish acronym), conducted by the country's National Statistical Institute (INEGI). The survey was conducted between May 18th and July 10th 2009, based on a stratified sampling frame that was designed to produce representative results at the level of the state and its rural and urban areas. It collected detailed data on each sampled household, and administered an additional extensive questionnaire to all female members of 15-49 years of age. This questionnaire collected detailed data on all pregnancies a woman had, whether or not they resulted in a miscarriage, and if so in which month of gestation. ${ }^{3}$

The unit of observation is a pregnancy, and the binary outcome of interest is whether or not it resulted in a miscarriage. The data available allow for the calculation of the month of onset of each pregnancy observed. To avoid truncation in the sample only pregnancies that started between January 2004 and July 2008 are included. After that date, pregnancies may still not have concluded by the time of the data were collected. A standard probit model is estimated with municipalityspecific and monthly (for each of the 55 months in the sample) fixed effects, implemented through the inclusion of a set of binary variables. The identifying assumption is thus that once municipality-specific time invariant characteristics are controlled for, the program roll-out can be treated as quasi-random. Put differently, the roll-out did not respond to changes in the outcome of interest or unobserved factors.

The treatment variable of interest is the relative level of roll-out in each month at the municipal level, constructed as the proportion of the number of beneficiaries in each month relative to the number in September 2011 (the last date available on a monthly basis, and the month when roll-out was supposed to be concluded). Given

\footnotetext{
2 The catalog detailing all covered interventions can be found on the Seguro Popular webpage at http:// www.seguro-popular.salud.gob.mx/images/contenidos/Causes/CAUSES2012.pdf.

3 See www.inegi.org.mx for a detailed description of the ENADID.
} 
that actual implementation occurred at the level of the locality, this is not an ideal measure of whether or not a woman was eligible for coverage during the pregnancy, but the best one that is available. The point estimates in the estimation must thus be interpreted as the estimated effect of complete program roll-out. In the most parsimonious specification the only right-hand side variables included are the treatment and the fixed effects.

Several previous studies have used the staggered roll-out as the treatment variable and shown that it is uncorrelated with municipal characteristics other than size (more rural areas were treated earlier) and the proportion of the uncovered population. The latter is to be expected as the program was first implemented in areas with little health coverage (Frenk et al. 2006). Most of the exogeneity tests provided in the literature essentially show that program roll-out was not affected by any other pre-analysis municipal characteristics. The upshot is that it should also be unaffected by any changes in these characteristics. Since municipal characteristics are usually only available every five or ten years, more direct panel-based tests with more frequent data are often infeasible. Bosch and Campos-Vázquez (2014) and Conti and Ginja (2014) use a binary treatment variable indicating whether or not a municipality participates in Seguro Popular (defined as having at least one beneficiary). The first paper tests for the exogeneity of treatment by regressing an index capturing quarter and year in which a municipality entered the program on municipality characteristics corresponding to the year 2000. The second paper runs a similar exercise using the year of implementation as the dependent variable. To my knowledge only paper that establishes exogeneity in a panel setting is Aterido et al. (2011), who show that changes in labor market informality had no causal effect on Seguro Popular enrollment in subsequent years. The treatment variable in the present paper (relative implementation of Seguro Popular relative to 2011) has already been used in Pfutze (2014). The treatment is shown to be exogenous by regressing its average value over the 2004-2010 time period on a large number of municipal characteristics, mostly taken from the 2005 census. Since state governments were involved in the program roll-out, different states proceeded at different speeds. However, once state level fixed effects were controlled for all variables, with exception of size and the initially uninsured population, turned out to be statistically not significant.

Results will also be presented for a specification with additional control variables. These are: a wealth index, the mother's age at the onset of the pregnancy and its squared value, the number of her previous pregnancies and miscarriages, and a binary indicator for being indigenous. Given that the data were collected in early/ mid 2009, only control variables that are time invariant are included. The wealth index is constructed based on a number of binary variables that capture dwelling characteristics and ownership of durable goods using principal components analysis. While the wealth index could be time variant, it can safely be assumed that it would only be changing fairly slowly. More than just being an additional control variable, the wealth index's main purpose is to identify asset poor households, as these are most likely to lack any other insurance coverage. Results will, therefore, be presented first for the full sample, followed by the subsample of households in the lowest three quintiles of the wealth index, which is interpreted as capturing the 
target population. Table 1 shows summary statistics on all variables discussed. After municipalities that have no variation in the outcome are excluded (which is necessary due to the municipality level fixed effects which would otherwise perfectly predict the outcome), the sample consists of 27,445 pregnancies. It can be seen that $11.4 \%$ of pregnancies in the samples resulted in a miscarriage, implying that the binary outcome variable denotes a relatively rare event. The average level of program roll-out is $25.9 \%$, for a few (small) municipalities this number is larger than one in some months due to an overall decline in their total population. The average age at the onset of a pregnancy is around 25 years of age, and $5.4 \%$ of women are indigenous.

Figure 1 gives a visual impression of the two main variables, the roll-out of Seguro Popular and the incidence of miscarriages. The former is presented by a solid line, while the latter is shown as a dashed line. The Seguro Popular roll-out is shown as the unweighted average across all municipalities in Mexico (i.e., not just the subset included in the 2009 ENADID). It had a relatively steady increase with the exception of two important spikes in late 2005 and 2006. The first one, which is also followed by no significant further increase over most of 2006, is probably explained by the fact that 2006 was a presidential election year. Mexican law prohibits the advertising of social programs during electoral campaigns (Blindaje Electoral). For that reason, the Health Ministry may well have decided to implement most of the planned expansion for 2006 in December 2005, before the start of the electoral season. The second spike corresponds to the implementation of the Seguro Médico para una Nueva Generación (SMNG) in December 2006. The SMNG expanded eligibility to Seguro Popular at no cost to any child born after December 1, 2006, and its immediate family. The incidence of miscarriages is shown according to the month a pregnancy started (not the month the miscarriage occurred). The data show a high degree of seasonality without any clear tendency over time. Given the high degree of variation, one would not expect to clearly see the effect of the program. There seems to be a slight increase in the second half of the time under study. This may just be a secular time effect, but one has also to keep in mind that the data used constitute a random sample of women, who were all interviewed in 2009, not of births. For one, memory bias will play a role if women

Table 1 Summary statistics

\begin{tabular}{llllll}
\hline Variable & Mean & Std. Dev. & Min. & Max. & N \\
\hline Miscarriage & 0.114 & 0.318 & 0 & 1 & 27,445 \\
Insurance at pregnancy & 0.259 & 0.23 & 0 & 1.222 & 27,445 \\
Wealth & -0.336 & 2.235 & -6.553 & 2.277 & 27,445 \\
Age & 25.113 & 6.459 & 10 & 50 & 27445 \\
Age squared & 672.389 & 346.237 & 100 & 2500 & 27,445 \\
Previous pregnancies & 1.398 & 1.545 & 0 & 15 & 27,445 \\
Previous miscarriages & 0.177 & 0.478 & 0 & 7 & 27,445 \\
Indigenous & 0.054 & 0.226 & 0 & 1 & 27,445 \\
\hline
\end{tabular}

Source ENADID 2009 


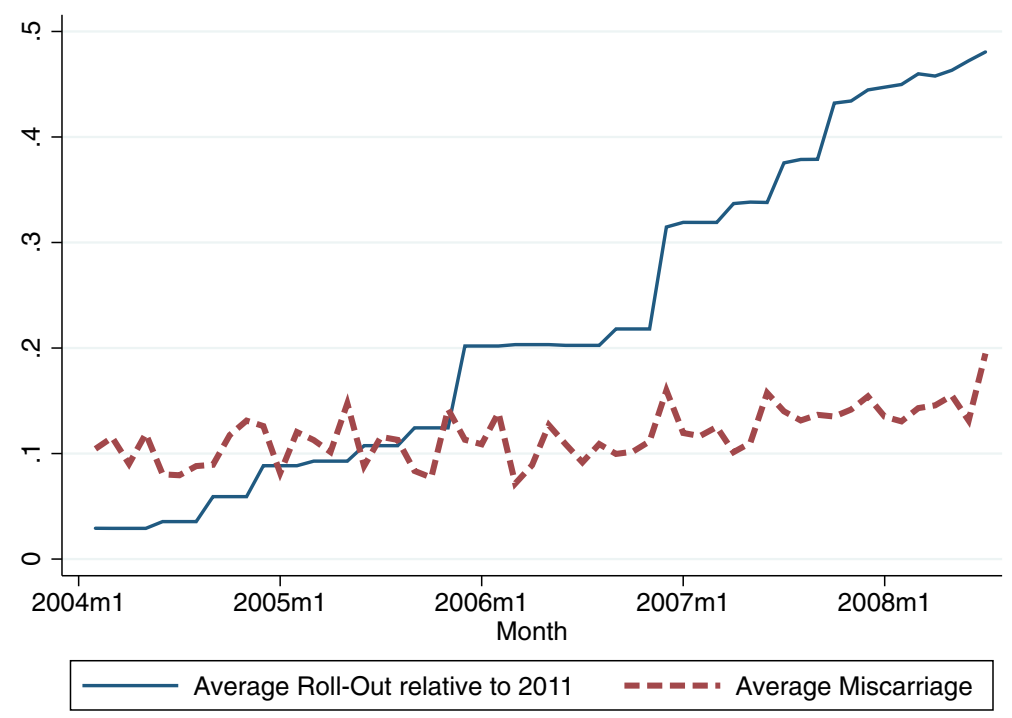

Fig. 1 Roll-Out of Seguro Popular at the national level and incidence of miscarriages in data used. Source ENADID 2009

do not remember all miscarriages further back in time. Moreover, for more recent births mothers are, on average, younger. For example, the proportion of teenage mothers increases from 21.5 to $23.2 \%$ and the average number of prior pregnancies drops from 1.47 to 1.33 . All these are associated with an increase in the risk of a miscarriage. In the analysis below, all these factors will be controlled for by monthly fixed effects and the additional control variables for mother's characteristics.

As just mentioned, one problem with data on miscarriages is that in many cases the event is unobserved by a woman. No reliable data on the overall incidence of miscarriages exist even for rich countries. This implies that a successful pregnancy (i.e., one resulting in a live birth) is more likely to be observed than one resulting in a miscarriage. This induces an obvious problem of potential selection on the outcome variable, which can be addressed using weighted exogenous sampling maximum likelihood (WESML) estimator first proposed by Manski and Lerman (1977) for the choice-based sampling. This estimator has also been applied by Pfutze (2014) to estimate the program's impact on infant mortality. It consists of applying to each observation $\mathrm{n}$ a weight defined as $w\left(i_{n}\right)=\frac{Q\left(i_{n}\right)}{H\left(i_{n}\right)}$; where $Q\left(i_{n}\right)$ denotes the population proportions of the outcome for observation n, and $H\left(i_{n}\right)$ denotes the same proportion in the sample. Since the true population proportions are unknown, the WESML will be run as a robustness check under two different hypothesized true population proportions of miscarriages (15 and 20\%) to verify whether results would change. It has to be pointed out that an undersampling of miscarriages would in any case only result in a negative bias on the estimator, i.e., working against finding statistically significant results. 


\section{Results}

Table 2 shows estimation results. The first two columns use the entire sample, and the remaining four only observation in the lowest three wealth quintiles. Specifications with and without controls are presented for the standard probit models in columns (1)-(4). The last two columns show results for the WESML estimator assuming that the true proportion of pregnancies that result in a miscarriage in the population is 15 and $20 \%$, respectively. The tables show parameter estimates and standard errors in parentheses. For ease of interpretation, at the bottom the table also shows the estimated marginal effect at the mean for the treatment variable.

As explained above, the treatment variable is an imperfect measure of whether or not a woman as eligible for the program during the pregnancy. It has rather to be interpreted as the probability of being eligible. The estimates are, therefore, intention to treat effects. Moreover, since actual eligibility is not observed, the effect can be expected to be statistically weaker. This is apparent in the table: While all the control variables are highly statistically significant, the treatment variable is so only at the $10 \%$ level. That said, the results on it are very consistent. As would be expected, the effect becomes stronger if the estimation is reduced to the target

Table 2 Results

\begin{tabular}{|c|c|c|c|c|c|c|}
\hline & (1) & (2) & (3) & (4) & (5) & (6) \\
\hline $\begin{array}{r}\text { Insurance at } \\
\text { pregnancy }\end{array}$ & $\begin{array}{l}-0.134 \\
(0.117)\end{array}$ & $\begin{array}{r}-0.140 \\
(0.119)\end{array}$ & $\begin{array}{r}-0.237 * \\
(0.135)\end{array}$ & $\begin{array}{r}-0.232^{*} \\
(0.137)\end{array}$ & $\begin{array}{r}-0.245^{*} \\
(0.142)\end{array}$ & $\begin{array}{r}-0.259^{*} \\
(0.148)\end{array}$ \\
\hline Wealth & & $\begin{array}{l}0.012 * * \\
\quad(0.006)\end{array}$ & & $\begin{array}{l}0.006 \\
\quad(0.007)\end{array}$ & $\begin{array}{l}0.006 \\
\quad(0.007)\end{array}$ & $\begin{array}{l}0.007 \\
\quad(0.008)\end{array}$ \\
\hline Age & & $\begin{array}{c}-0.068 * * * \\
(0.011)\end{array}$ & & $\begin{array}{c}-0.058 * * * \\
(0.013)\end{array}$ & $\begin{array}{c}-0.060 * * * \\
(0.013)\end{array}$ & $\begin{array}{c}-0.061 * * * \\
(0.014)\end{array}$ \\
\hline Age squared & & $\begin{array}{l}0.002 * * * \\
(0.0002)\end{array}$ & & $\begin{array}{l}0.002 * * * \\
(0.0002)\end{array}$ & $\begin{array}{l}0.002 * * * \\
(0.0002)\end{array}$ & $\begin{array}{l}0.002 * * * \\
(0.0003)\end{array}$ \\
\hline $\begin{array}{l}\text { Previous } \\
\text { pregnancies }\end{array}$ & & $\begin{array}{c}-0.046 * * * \\
(0.009)\end{array}$ & & $\begin{array}{c}-0.054 * * * \\
(0.011)\end{array}$ & $\begin{array}{c}-0.056 * * * \\
(0.011)\end{array}$ & $\begin{array}{c}-0.058^{* * * *} \\
(0.011)\end{array}$ \\
\hline $\begin{array}{l}\text { Previous } \\
\text { miscarriages }\end{array}$ & & $\begin{array}{r}0.155^{* * * *} \\
(0.022)\end{array}$ & & $\begin{array}{r}0.135 * * * \\
(0.028)\end{array}$ & $\begin{array}{r}0.141 * * * \\
(0.029)\end{array}$ & $\begin{array}{l}0.148 * * * \\
\quad(.030)\end{array}$ \\
\hline Indigenous & & $\begin{array}{r}-0.111 * \\
(0.064)\end{array}$ & & $\begin{array}{c}-0.139 * * \\
(0.068)\end{array}$ & $\begin{array}{c}-0.146 * * \\
(0.070)\end{array}$ & $\begin{array}{c}-0.154 * * \\
(0.073)\end{array}$ \\
\hline Obs. & 27,445 & 27,445 & 19,100 & 19,100 & 19,100 & 19,100 \\
\hline $\begin{array}{l}\text { Marginal effect at } \\
\text { mean }\end{array}$ & -0.025 & -0.025 & -0.041 & -0.039 & -0.051 & -0.067 \\
\hline Wealth Quintiles & All & All & $1-3$ & $1-3$ & $1-3$ & $1-3$ \\
\hline $\begin{array}{l}\text { Assumed True } \\
\text { Population Risk }\end{array}$ & None & None & None & None & $15 \%$ & $20 \%$ \\
\hline
\end{tabular}

$* * *, * *$, and $*$ denote statistical significance at the 1, 5, and $10 \%$ levels, respectively. Results for probit model with robust standard errors on binary variable indicating a miscarriage. Parameter estimates shown in main table with $p$ values in parenthesis, the corresponding marginal effect at the mean for exposure to insurance is shown below the number of observations. All specifications include year-month and municipality level fixed effects. Source ENADID 2009 
population in columns (3)-(6). The point estimates stay practically constant for result within each sample, despite adding a number of highly significant controls. Neither does the WESML change the point estimates.

The implied marginal effects at the mean need to be interpreted carefully, since the numbers presented refer to the counterfactual of complete program roll-out, evaluated at the point of the largest marginal effect. Referring back to Table 1, for the lowest three wealth quintiles, a one percentage point increase in roll-out, would imply a reduction of $0.04 \%$ point, or around $0.33 \%$ relative to the sample mean. Assuming different population proportions, the marginal effect continues to be around $0.33 \%$. In terms of standard deviations, the reduction of a one standard deviation increase in program coverage implies roughly a one percentage point (or slightly less than $10 \%$ ) reduction in miscarriages.

These figures can be put into concrete numbers of pregnancies saved. Under the assumption that the program had no effect on households in the top two wealth quintiles, I will focus only on the results in column (4) of Table 2. Using sampling weights, the data indicate that there has been a total of 630,331 miscarriages among households in the bottom three wealth quintiles over the period of four years and seven months under study. The estimation results imply that in the absence of the program that number would have been 678.317. Put differently, over this time period Seguro Popular saved an estimated 47,986 pregnancies. It has to be kept in mind that the average roll-out was only $25.9 \%$. Under the counterfactual that the program had been fully implemented over the entire period, it would have saved an estimated 213.339 pregnancies, or around 46,500 per year. This means that it would reduce the risk of a miscarriage by approximately $30 \%$ for the targeted group (of which not all will participate in the program). The latter results should, however, be taken with a grain of salt as they assume a linear effect of program coverage on the risk of miscarriage. Yet, if the most vulnerable population was treated first, as it seems to have been the case, one would expect decreasing marginal effects as the program expanded further.

The point estimates on the control variables are of no direct interest, but merit some brief discussion. The risk of a miscarriage follows an U-shaped pattern in age (larger at low ages and high ages), and decreases in the number of previous pregnancies. Having had more miscarriages prior to the current pregnancies increases the risk of having another one, which probably captures woman-specific risks. All these results would be expected. The two somewhat counterintuitive findings are the positive effect in the wealth index and the negative one on the dummy of being indigenous. The likely reason is that they may proxy for other unobserved factors such as better medical knowledge (and general awareness whether or not a miscarriage occurred) or cultural factors that affect whether the respondent is willing to admit to prior miscarriages. The important insight from the control variables is that their inclusion does not change the estimates on the treatment, providing strong evidence for the exogenous nature of program roll-out. 


\section{Conclusions}

This study provided convincing evidence that access to the de-facto noncontributory health insurance program Seguro Popular in Mexico resulted in decreased risk of miscarriages. It has been estimated that the program reduced the number of miscarriages in the country by 47,986 during its first four years and seven months of operation and before having been fully implemented. This result is important in two respects. First, it confirms that access to basic health care has an important and measurable effect on pregnancy risks with important direct welfare effects. Second, it also shows that the program did have a measurable positive effect on health outcomes that can be expected to change in the short-term. This is an important general result for the future design of Seguro Popular, and also for policy makers in other countries that try to extend basic heath care services to the entire population. It also bodes well for possible effects on longer-term health outcomes, which will be much more difficult to establish and should be the focus of future research.

Open Access This article is distributed under the terms of the Creative Commons Attribution 4.0 International License (http://creativecommons.org/licenses/by/4.0/), which permits unrestricted use, distribution, and reproduction in any medium, provided you give appropriate credit to the original author(s) and the source, provide a link to the Creative Commons license, and indicate if changes were made.

\section{References}

Aterido R, Hallward-Driemeier M, Pagés C (2011) Does Expanding Health Insurance Beyond FormalSector Workers Encourage Informality? Measuring the Impact of Mexico's Seguro Popular, IZA Discussion Paper No 5996

Azuara O, Marinescu I (2013) Informality and the expansion of social protection programs. Evidence from Mexico. J Health Econ 33:181-197

Barros R (2008) Wealthier but not much healthier: effects of a health insurance program for the poor in Mexico. (unpublished working paper)

Bleich SN, Cutler DM, Adams AS, Lozano R, Murray CJ (2007) Impact of insurance and supply of health professionals on coverage of treatment for hypertension in Mexico: population based study. Br Med J 335(7625):875-878

Bosch M, Campos-Vázquez RM (2014) The trade-offs of social assistance programs in the labor market: the case of the "Seguro Popular. Program in Mexico". Am Econ J: Econ Policy 6(4):71-99

Camacho A, Conover E, Hoyos A (2014) Effects of Colombia's social protection system on workers. Choice between formal and informal employment. World Bank Econ Rev 28(3):446-466

Campos-Vázquez R, Knox MA (2013) Social protection programs and employment: the case of Mexico's seguro popular program. Econ Mex 22(2):403-448

Conti G, Ginja R (2014) Evaluating a Universal Health Insurance Program: evidence from Mexico. (Unpublished working paper)

Duval-Hernández R, Smith-Ramírez R (2011) Informality and Seguro Popular under Segmented Labor Markets. (unpublished working paper)

Frenk J, González-Pier E, Gómez-Dantes O, Lezana MA, Knaul FM (2006) Comprehensive reform to improve health system performance in Mexico. Lancet 368:1524-1534

Gakidou E, Lozano R, González-Pier E, Abbott-Klafter J, Barofsky JT, Bryson-Cahn C, Feehan DM, Lee DK, Hernández-Llamas H, Murray CJ (2006) Assessing the effect of the 2001-06 Mexican health reform: an interim report card. Lancet 368:1920-1935

Grogger J, Arnold T, León AS, Ome A, Triyana M (2010) Identificación y análisis de los efectos del Seguro Popular en el gasto en salud de los afiliados, Discussion paper, Centro de Investigación y 
Docencia Económicas, Evaluation commissioned by the Comisión Nacional de Protección Social en Salud (CNPPS)

King G, Gakidou E, Imai K, Lakin J, Moore RT, Nall C, Ravishankar N, Vargas M, Tellez-Rojo MM, Hernández-Avila JE, Hernández-Avila M, Hernández-Llamas H (2009) Public policy for the poor? A randomized assessment of the Mexican universal health insurance programme. Lancet 373:1447-1454

Knaul FM, Arreola-Ornelas H, Méndez-Carniado O, Bryson-Cahn C, Barofsky J, Maguire R, Miranda M, Sesma S (2006) Evidence is good for your health system: policy reform to remedy catastrophic and impoverishing health spending in Mexico. Lancet 368:1828-1841

Knox M (2008) Health insurance for all: an evaluation of Mexico's Seguro popular program. (Unpublished working paper)

Lakin JM (2010) The End of Insurance? Mexico’s Seguro Popular, 2001-2007. J Health Politics Policy and Law 35(3)

Levy S (2008) Good intentions, bad outcomes: social policy. Informality and economic growth in Mexico. Brookings Institution Press, Washington, D.C

Manski CF, Lerman SR (1977) The estimation of choice probabilities from choice based samples. Econometrica 45(8):1977-1988

Martínez G, Aguilera N (2010) The value of health and longevity in Mexico. CISS Working Paper No. 1003

Pfutze T (2014) The effects of Mexicos seguro popular health insurance on infant mortality: an estimation with selection on the outcome variable. World Dev 59:475-486

Ruvalcaba LN, Parker S (2010) Identificación y análisis de los efectos en las condiciones de salud de los afiliados al Seguro Popular. Discussion paper, Centro de Investigación y Docencia Económicas, Evaluation commissioned by the Comisión Nacional de Protección Social en Salud (CNPPS)

Scott J, Aguilera N (2010) Análisis de la factibilidad, alternativas de diseño y consecuencias distributivas de la construcción de un sistema integrado de salud en México. Discussion paper, Centro de Investigación y Docencia Económicas, Evaluation commissioned by the Comisión Nacional de Protección Social en Salud (CNPPS)

Sosa-Rubi SG, Galarraga O, Harris JE (2009) Heterogeneous impact of the Seguro Popular program on the utilization of obstetrical services in Mexico, 2001-2006: a multinomial probit model with a discrete endogenous variable. J Health Econ 28(1):20-34 